\title{
PENGEMBANGAN MEDIA GRAFIS DALAM PEMBELAJARAN
}

\author{
Ahmad Manshur \\ Institut Agama Islam Sunan Giri Bojonegoro \\ manshur@sunan-giri.ac.id \\ Akhmad Rodhi \\ Magister Pendidikan Agama Islam \\ Institut Agama Islam Sunan Giri Bojonegoro \\ akhmad@gmail.com
}

\begin{abstract}
The use of media in the learning process is very important to support the learning process, in the modern era, graphic media is the most attractive medium, by using graphic media children can understand messages and help them to be more motivated to learn, the problem is when Graphic media is not able to develop and monotonous will make students tend to be bored and reduce motivation to learn, this paper, development of graphic media is something needs to develop, the affect children become active and have high learning motivation, several graphic media need to be developed such as Graphics, diagrams, charts, sketches, posters, comics, photo media, flannel boards and bulletin boards, educators (teachers) can present graphic media through visual media presenting, ideas through the presentation of words, sentences with numbers, and symbols or pictures. Graphics are used to attract attention, clarify the presentation of ideas, and illustrate facts, they are interesting and memorable. The advantages of graphic media can simplify and accelerate students' understanding of the message conveyed, increase student attention, and an affordable price. While the weakness of graphic media is requires special skills in its manufacture, especially for more complex graphics and the presentation of messages is only a visual element.
\end{abstract}

Keywords: Development, Grafis Media, Learning Process

\section{A. Pendahuluan}

Perkembangan psikologi peserta didik saat ini harus beriringan dengan perubahan dunia pendidikan yang berdasarkan dinamika sosial, serta dinamika 
sistem pendidikan. ${ }^{1}$ Sebagaimana dalam UU kita yang menjelaskan bahwa pendidikan diindonesia harus didasarkan pada perkembangan nilai karakter yang disesuikan dengan perkembangan iptek saat ini. ${ }^{2}$

Nurdyansyah memperejelas Dunia pendidikan harus berinovasi secara keseluruhan. Artinya semua perangkat dalam sistem pendidikan memiliki peran dan menjadi faktor yang berpengaruh penting dalam keberhasilan sistem pendidikan. $^{3}$

Pelibatan berbagai pihak dalam optimalisasi proses pembelajaran menjadi mutlak diperlukan untuk tercapaianya tujuan pembelajaran. ${ }^{4}$ Seseorang dapat diartikan belajar apabila telah mencapai tujuan dalam pembelajaran dan mampu melaksanaan pengalaman pembelajaran yang diciptakan untuk pencapaian tujuan tertentu. ${ }^{5}$

Tujuan pembelajaran tidak akan berjalan baik tanpa adanya penilaian hasil pembelajaran yang tepat dan sesui dengan karakter materi ajar. Karena sebuah penilaian yang baik memerlukan sebuah analisis yang akurat dan pengolahan yang tepat dan efektif. ${ }^{6}$

Untuk dapat menjalankan proses pembelajarn dengan baik sampai dengan penilaian dan evaluasi memerlukan media yang tepat dalam pelaksanaanya. Salah satu media yang digunakan adalah media grafis. Media grafis termasuk media visual. Sebagaimana media lain media grafis juga mempunyai beberapa fungsi diantaranya menyalurkan pesan dari sumber ke penerima pesan. Dalam penerima pesan, banyak di tuangkan dalam bentuk simbol-simbol komunikasi visual. Simbolsimbol tersebut perlu dipahami benar artinya agar proses penyampaian pesan

\footnotetext{
${ }^{1}$ M. Musfiqon dan Nurdyansyah. N. (2015). Pendekatan Pembelajaran Saintifik. Sidoarjo: Nizamia learning center., 41

2 Nurdyansyah \& Luly Riananda. (2016). Developing ICT-Based Learning Model to Improve Learning Outcomes IPA of SD Fish Market in Sidoarjo, Proceedings of International Research Clinic \& Scientific Publications of Educational Technology. Jurnal TEKPEN, Jilid 1, Terbitan 2, 929-930.

${ }^{3}$ Nurdyansyah, Pandi Rais, Qorirotul Aini. (2017). The Role of Education Technology in Mathematic of Third Grade Students in MI Ma'arif Pademonegoro Sukodono. Madrosatuna: Journal of Islamic Elementary School Vol. 1 (1), November 2017, 37-46 ISSN 2579. 38.

4 Nurdyansyah. N., Andiek Widodo, Inovasi Teknologi Pembelajaran. (Sidoarjo:Nizamia Learning Center,2015), 2.

5 Nurdyansyah. N., Eni fariyarul Fahyuni, Inovasi Model Pembelajaran Sesuai Kurikulum 2013 (Sidoarjo:Nizamia Learning Center,2016), 1.

6 Nurdyansyah. N., Andiek Widodo, Manajemen Sekolah Berbasis ICT. (Sidoarjo:Nizamia Learning Center,2015), 103
} 
dapat berhasil dan efisien, serta untuk definisi tersebut dipadukan dengan pengertian praktis, maka grafis sebagai media, dapat mengkomunikasikan faktafakta dan gagasan-gagasan secara jelas.

Pengungkapan itu bisa berbentuk diagram, sketsa atau grafik. Kata-kata dan angka-angka dipergunakan sebagai judul dan penjelasan kepada grafik, bagan, diagram, poster kartun dan komik. Sedangkan sketsa, lambang, dan bahkan foto dipergunakan pada media grafis untuk mengartikan fakta, pengertian dan gagasan yang pada hakikatnya penyampaian presentasi grafis. ${ }^{7}$

\section{B. Pembahasan}

a. Media Grafis

Media grafis adalah media visual yang menyajikan fakta, ide atu gagasan melalui penyajian kata-kata, kalimat angka-angka, dan simbol atau gambar. Grafis biasanya digunakan untuk menarik perhatian, memperjelas sajian ide, dan mengilustrasikan fakta-fakta sehingga menarik dan diingat orang. ${ }^{8}$ Menurutu para ahli medi grafis yaitu :

a. Nana Sudjana dan Ahmad Rifai, media grafis sebagai media yang mengkombinasikan fakta an gagasan secara jelas dan kuat melalu suatu kombinasi pengungkapan kata-kata dan gambar-gambar.

b. Ahmad Rohani, Media grafis merupakan media visual yang menyajikan fakta ide dan gagasan melalaui kata-kata, kalimat, angka-angka, dan bebbagai simbol atau gambar.

c. Senat dalam Suharjo, Media grafis adalah suatu penyajikan secara visual yang menggunakan titik-titik, garis-garis, tulisan, dan simbol visual yang lain dengan maksud untuk menggambarkan dan merangkum suatu ide, data atau kajian.

Dari beberapa pendapat diatas dapaat di pahami bahwa media grafis adalah semua media visual yang menyajikan fakta, gagagsan atau kejadian melalui kombinasi pengungkapan kata, kalimat, angaka,gambar, ataupun

\footnotetext{
${ }^{7}$ http://puspadyani.blogspot.co.id/2016/06/makalah-penggunaan-media-grafis-dalam_73.html

${ }^{8}$ Susilana, Rudi \& Riyana, Cepti, Media Pembelajaran Hakikat,Pengembangan, Pemanfaatan dan Penilaian, CV. Wacana Prima, Bandung,2009.14
} 
simbol-simbol visual yang lain. Media grafis ini mengutamakan indera penglihatan dengan menuangkan simbol omunikasi visual dan simbol pesan yang harus dipahami. ${ }^{9}$

b. Macam-macam Media Grafis

Yang termasuk media grafis antara lain :

1. Grafik, yaitu penyajian data berangkat melalui perpaduan antara angka, garis dan simbol.

2. Diagram, yaitu gambaran yang sederhana yang dirancang untuk memperlihatkan hubungan timbal balik yang biasanya disajikan melalui garis-garis simbol.

3. Bagan, yaitu perbaduan sajian kata-kata, garis, dan simbol yang merupakan ringkasan suatu proses, perkembangan atau hubunganhubungan penting.

4. Sketsa, yaitu gambar yang sederhana atau draf kasar yang melukiskan bagian-bagian pokok dari suatu bentuk gambar.

5. Poster, yaitu sajian kombinasi visual yang jelas, menyolok dan menarik denagn maksud untuk menarik perhatian orang yang lewat.

6. Komik, yaitu bentuk kartun yang mengungkapkan karakter dan menerapkan suatu cerita dalam urutan yang erat hubungannya dengan gambar dan dirancang untuk memberikan hiburan kepada para pembaca.

7. Media foto, yaitu gambar diam (still picture) artinya sajian visual dalam foto tidak bergerak.

8. Papan flanel, yaitu papan yang belapis kain flanel untuk menyajikan gambar atau kata-kata yang mudah ditempel dan mudah pula dilepas.

9. Bulletin Board, yaitu papan biasa tanpa dilapisi kain flanel. Gambargambar atau tulisan-tulisan biasanya langsung ditempelkan dengan menggunakan lem atau alat penempel lainnya. ${ }^{10}$

9 Siti Maisaroh, Penggunaan Media Grafis Pada Pembelajaran Pendidikan Kwarganegaraan dikelas Iva.2013.17

10 Susilana, Rudi \& Riyana, Cepti, Media Pembelajaran Hakikat,Pengembangan, Pemanfaatan dan Penilaian, CV.Wacana Prima, Bandung, 2009..15 
c. Kelebihan dan Kekurangan Media Grafis dalam Proses Pembelajaran Kelebihan media grafis :

1. Dapat mempermudah dan mempercepat pemahaman siswa terhadap pesan yang di sampaikan.

2. Dapat dilengkapi dengan warna-warna sehingga lebih menarik.

3. Pembuatannya mudah dan harganya murah.

4. Memperbesar perhatian siswa

5. Membantu mengatasi keterbatasan siswa. ${ }^{11}$

Kelemahan media grafis :

1. Membutuhkan keterampilan khusus dalam pembuatannya, terutama untuk grafis yang lebih kompleks.

2. Penyajian pesan hanya berupa unsur visual.

d. Penggunaan Media Grafis Dalam Pembelajaran

1. Grafik

Grafik divisualisasikan dengan bantuan objek dalam bentuk garis, batang dan gambar. Menampilkan pesan dalam bentuk-bentuk seperti itu mempermudah penyerapan informasi oleh siswa. Terlebih jika gambar-gambar tersebut sudah dikenali siswa sebelumnya. Grafik paling baik digunakan oleh dalam pembelajaran pada materi berupa ringkasan pelajaran setelah siswa memperoleh informasi lain dari berbagai sumber baik buku atau penjelasan sebelumnya dari guru sendiri.

Para siswa tidak akan mengalami kesulitan dalam memahami pesan yang disajikan melalui grafik, hal tersebut disebabkan karena grafik sendiri bukan sesuatu yang asing bagi siswa. Mereka sebelumnya mungkin melihat contoh grafik dari majalah, koran tabliod atau internet. Namun yang terpenting grafik menggambarkan informasi secara ringkas.

11 Http://m3njadipintar.blogspot.co.id/2017/02/fungsi-kelebihan-dan-kekurangan-media-grafis.html. Diakses pada tgl 22 november 2017 pukul 14.13. 
Memperoleh grafik sekarang ini bukanlah sesuatu yang sulit. Sekedar mencarikan contoh grafik guru dengan mudah dapat memperolehnya di majalah, koran, dan internet. Jika grafik ingin disesuaikan dengan materi, maka dengan mudah guru dapat membuatnya sendiri. Terdapat beberapa program aplikasi melalui komputer untuk membuat grafik dengan mudah. Guru tinggal memasukan data, memilih bentuk grafik yang dikehendaki, memilih warna dan langsung dapat memiliki grafik yang menarik. Misalnya membuat grafik mellaui program Microsoft Word, Excel dan powerpoint. ${ }^{12}$

Contoh pembelajaran matematika menggunakan media grafik lingkaran yang membahas tentang pecahan angka satuan puluhan, ratusan, pecahan dalam bentuk persen, dan pecahan bentuk persetengah, pertiga, ataupun perempat.

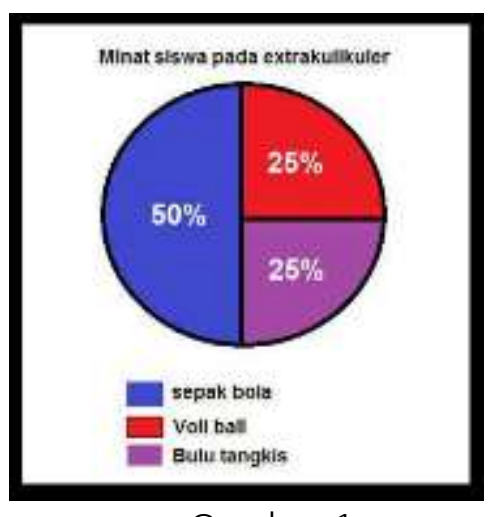

Gambar.1

2. Bagan

Pemilihan Bagan. Bagan yang akan disajikan di kelas tentu saja harus berkaitan dengan materi yang akan disampaikan. Guru yang kreatif dapat merancang bagan sendiri dengan terlebih dahulu menganalisis materi dan mempersiapkannya untuk dibuat dalam bentuk bagan. Bagan yang baik haruslah memiliki 2016.39

${ }^{12}$ Kustiawan Usep,Pengembangan Media Pembelajaran Anak Usia Dini, Gunung Samudra, Malang, 
kesesuaian dengan materi tidak miss concept atau tidak terdapat kesalahan-kesalahan konsep, data atau informasi. Selain itu harus menarik yang ditandai dengan pemilihan warna yang tepat, harmonis dan tidak terkesan terlalu rame. Informasi yang disajikan dalam bentuk teks memiliki keterbacaan tinggi (visual literacy) sehingga dalam jarak agak jauh masih terbaca dengan baik.

Dalam pembelajaran, siswa dapat didesain dengan berbagai macam pola pengaturan, termasuk penggunaan bagan. Jika penggunaan bagan untuk siswa dalam kelompok besar (big group) maka siswa dipersiapkan dengan cara klasikal dan tidak perlu pengelompokan secara khusus. Sebaliknya jika siswa perlu dikelompokan maka siapkanlah terlebih dahulu pola pengaturannya, berdasarkan apa pengelompokannya, berapa jumlah masing-masing kelompoknya, dan sebagainya sehingga jika pengaturan ini secara spontan dipikirkan oleh guru pada saat di kelas akan menyita waktu. Dengan demikian guru perlu memikirkannya dari awal sebelum pembelajaran dimulai. ${ }^{13}$

Contoh pembelajaran pendidikan kewarganegaraan tentang materi susunan organisasiyang ada di sekolah dengan menggunakan media bagan chart.

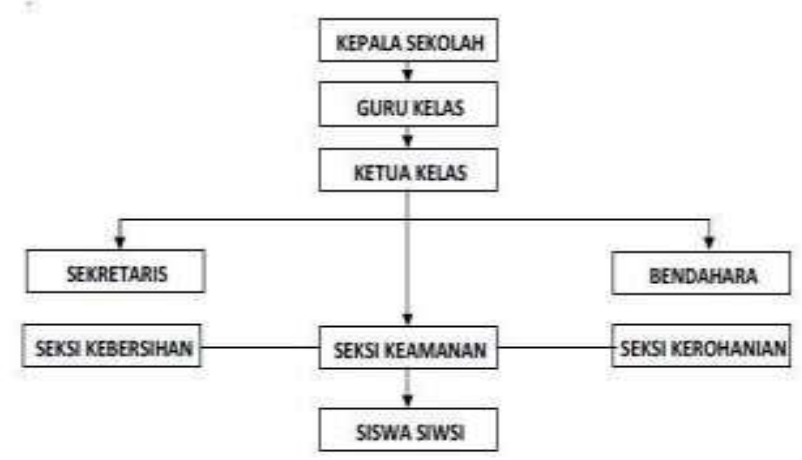

Gambar.2

${ }^{13}$ Kustiawan Usep,Pengembangan Media Pembelajaran Anak Usia Dini, Gunung Samudra, Malang, 2016.34 
3. Komik

Begitu maraknya komik di masyarakat dan begitu tingginya kesukaan akan-akan terhadap komik hal tersebut mengilhami untuk dijadikannya komik sebagai media pembelajaran. Salah satu kelebihan dari komik seperti penelitian yang dilakukan Thorndike, diketahui bahwa anak yang membaca komik lebih banyak misalnya dalam sebulan minimal satu buah buku komik maka sama dengan membaca buku-buku pelajaran dalam setiap tahunnya, hal ini berdampak pada kemampuan membaca siswa dan penguasaan kosa kata jauh lebih banyak dari siswa yang tidak menyukai komik.

Hal inilah yang juga menginspirasi komik yang isinya materimateri pelajaran. Kecenderungan yang ada siswa tidak begitu menyukai buku-buku teks apalagi yang tidak disertai gambar dan ilustrasi yang menarik. Padahal secara emprik siswa cenderung lebih menyukai buku yang bergambar, yang penuh warna dan divisualisasikan dalam bentuk realistis maupun kartun. Komik pembelajaran diharapkan mampu meningkatkan minat siswa untuk membaca sehingga pada akhirnya mampu meningkatkan hasil belajar siswa. ${ }^{14}$

Contoh pembelajaran matematika menggunakan media komik dengan materi penjumlahan.

${ }^{14}$ Kustiawan Usep,Pengembangan Media Pembelajaran Anak Usia Dini, Gunung Samudra, Malang, 2016.32 


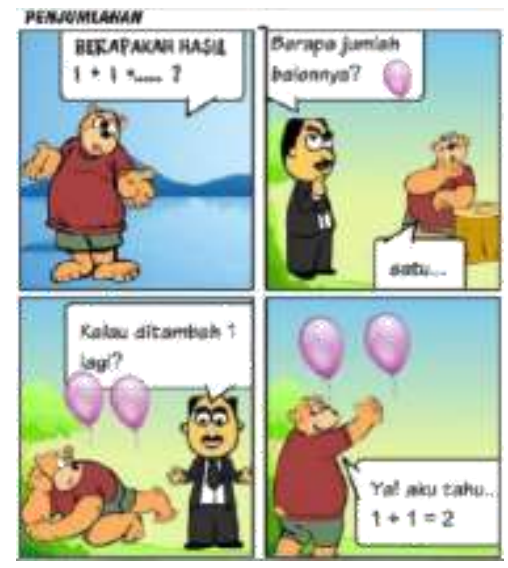

Gambar.3

4. Poster

Menggunakan poster untuk pembelajaran dapat dilakukan dengan dua cara yaitu :

a) Digunakan sebagai bagian dari kegiatan belajar mengajar, dalam hal ini poster digunakan saat guru menerangkan sebuah materi kepada siswa, begitu halnya siswa dalam mempelajari materi menggunakan poster yang disediakan oleh guru. Poster yang digunakan ini harus relevan dengan tujuan dan materi. Poster disediakan guru baik dengan cara membuat sendiri maupun dengan cara membeli / menggunakan yang sudah ada. Misalnya guru membelajarkan siswa tentang teknik menulis karangan naratif tentang pentingnya buang sampah pada tempatnya. Kemudian guru memasang sebuah poster tentang akibat membuang sampah sembarangan. Guru menugaskan siswa untuk mengamati poster tersebut lalu kemudian siswa diperintahkan untuk membuat karangan berdasarkan poster tersebut.

b) Digunakan di luar pembelajaran yang bertujuan untuk memotivasi siswa, sebagai peringatan, ajakan, propaganda atau ajakan untuk melakukan sesuatu yang postitif dan penanaman 
nilai-nilai sosial dan keagamanaan. Dalam hal ini poster tidak digunakan saat pembelajaran namun di pajang di dalam kelas atau disekitar sekolah di tempat yang strategis agar terlihat dengan jelas oleh siswa. Misalnya ajakan untuk rajin menabung, senantiasa membuang sampah pada tempatnya, mengingatkan untuk melaksanakan ibadah, tidak mencontek, dan lain-lain. Perbedaan antara poster yang digunakan dalam pembelajaran dan diluar pembelajaran tidak memiliki perbedaan yang mendasar. Perbedaannya hanya pada penyimpanan, dan tematema yang dipilih, untuk poster pembelajaran biasanya mengangkat tema-tema yang spesifik sesuai dengan kurikulum, sedangkan poster untuk pajangan biasanya menggunakan tema-tema umum dan universal sehingga tidak lapuk oleh zaman. Kedua jenis poster tersebut jika dilihat dari teknik dan prinsip-prinsip pembuatannya sama tidak memiliki perbedaan ${ }^{15}$

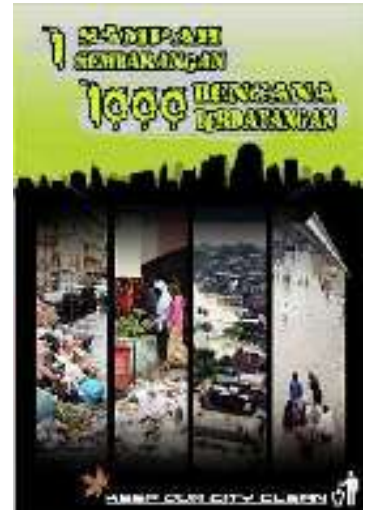

Gambar.4

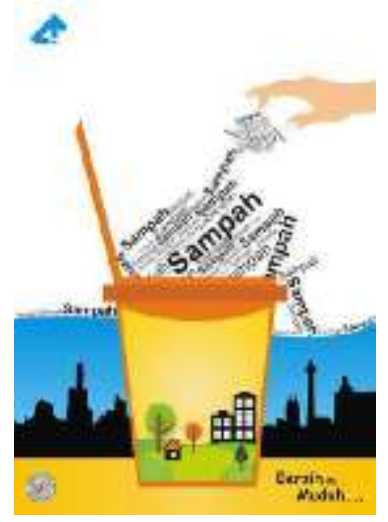

Gambar.5

5. Media Foto

Pergunakanlah gambar sesuai kebutuhannya tidak terlalu banyak, namun memiliki relevansi tinggi dengan materi yang sedang

${ }^{15}$ Kustiawan Usep,Pengembangan Media Pembelajaran Anak Usia Dini, Gunung Samudra, Malang, 2016.31 
diajarkan. Jumlah gambar yang sedikit namun terpilih akan lebih baik dari pada gambar yang banyak tetapi kurang memberikan makna. Ilustrasi foto yang berlebihan justru akan menganggu konsentrasi dan fokus perhatian siswa akan terbagi kepada gambargambar tersebut. Jadi yang terpenting adalah pemusatan perhatian pada gagasan utama.

Kurangilah penambahan kata-kata pada ilustrasi foto. Foto sangat penting dalam mengembangkan kata-kata atau cerita atau gagasan baru. Misalnya pada pelajaran sejarah, siswa dengan mengamati gambar-gambar candi gaya Jawa Tengah dan Jawa Timur menjelaskan mengapa bentuknya tidak sama apa ciri-ciri yang membedakan satu dengan yang lainnya. Gurun pasir misalnya, mungkin tidak begitu dikenali oleh siswa yang berada didaerah pegunungan tropis, begitu juga dengan istilah mall tidak akrab di telinga siswa yang berada didaerah terpencil. Dengan menggunakan foto itulah siswa akan memperoleh kejelasan informasi verbal. Guru seharusnya menyadari bahwa dengan mengurangi deskripsi katakata atau verbal kepada foto-foto yang ditunjukannya akan dirasakan manfaatnya terutama bagi para siswa pemula belajar membaca. ${ }^{16}$

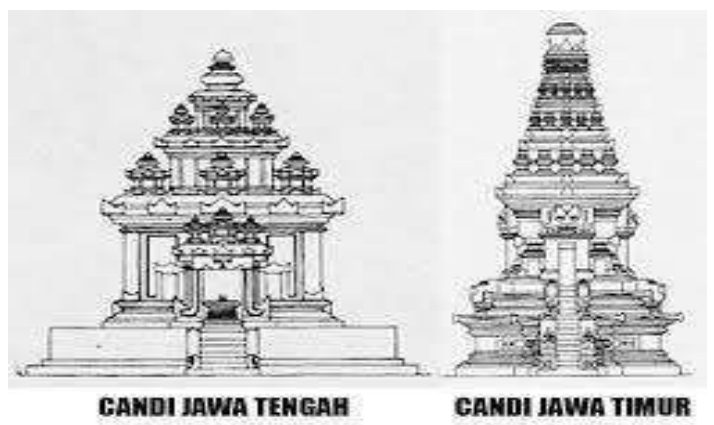

Gambar.6

${ }^{16}$ Kustiawan Usep,Pengembangan Media Pembelajaran Anak Usia Dini, Gunung Samudra, Malang, 2016.49 


\section{E. Kesimpulan}

Media grafis adalah media visual yang menyajikan fakta, ide atu gagasan melalui penyajian kata-kata, kalimat angka-angka, dan simbol atau gambar. Grafis biasanya digunakan untuk menarik perhatian, memperjelas sajian ide, dan mengilustrasikan fakta-fakta sehingga menarik dan diingat orang.

Macam-macam media grafis terdiri dari grafik, diagram, bagan, siklus, poster, komik, media foto,papan fallanel dan bulettin board.

Kelebihan media grafis yaitu Dapat mempermudah dan mempercepat pemahaman siswa terhadap pesan yang di sampaikan, memperbesar perhatian siswa, dan harga yang terjangkau. Sedangkan kelemahan media grafis yaitu Membutuhkan keterampilan khusus dalam pembuatannya, terutama untuk grafis yang lebih kompleks dan penyajian pesan hanya berupa unsur visual.

Kegunaan media grafis dalam pembelajaran yaitu sebagai media yang mudah digunakan dan bertujuan mempermudah siswa untuk memahami pesan pembelajaran yang telah disampaikan. 


\section{DAFTAR PUSTAKA}

Kustiawan, Usep, 2016. Pengembangan Media Pembelajaran Anak Usia

Dini.Gunung Samudra, Malang:

Maisaroh, Siti. Penggunaan Media Grafis Pada Pembelajaran Pendidikan Kwarganegaraan dikelas IV a.2013.

Muhammad, M., \& Nurdyansyah, N. (2015). Pendekatan Pembelajaran Saintifik. Sidoarjo: Nizamia learning center.

Nurdyasnyah, N., \& Andiek, W. (2015). Inovasi teknologi pembelajaran. Sidoarjo: Nizamia learning center.

Nurdyansyah, N., \& Fahyuni, E. F. (2016). Inovasi Model Pembelajaran Sesuai Kurikulum 2013. Sidoarjo: Nizamia learning center.

Nurdyansyah, N., Rais, P., \& Aini, Q. (2017). The Role of Education Technology in Mathematic of Third Grade Students in MI Ma'arif Pademonegoro Sukodono. Madrosatuna: Journal of Islamic Elementary School, 1(1), 37-46.

Nurdyansyah, N. (2016). Developing ICT-Based Learning Model to Improve Learning Outcomes IPA of SD Fish Market in Sidoarjo. Jurnal TEKPEN, 1(2).

Nurdyasnyah, N., \& Andiek, W. (2017). Manajemen Sekolah Berbasis ICT. Sidoarjo: Nizamia learning center.

Susilana, Rudi \& Riyana, Cepti, Media Pembelajaran Hakikat,Pengembangan, Pemanfaatan dan Penilaian, CV. Wacana Prima, Bandung:2009.

http://belajarpsikologi.com/pengertian-media-pembelajaran/, 22 November 2017 pukul 13.15

Http://m3njadipintar.blogspot.co.id/2017/02/fungsi-kelebihan-dankekurangan-media-grafis.html. Diakses pada tgl 22 november 2017 pukul 14.13. 